\title{
Utilising MFrac Technique to Simulate Hydraulic Fracturing Process
}

\author{
Al-Shukri MDA* \\ School of Computing, Science \& Engineering (Petroleum and Gas Engineering), \\ University of Salford, Manchester, United Kingdom \\ *Corresponding author: Mabrouk DA Al-Shukri, School of Computing, Science \& \\ Engineering (Petroleum and Gas Engineering), University of Salford, Manchester, \\ United Kingdom, M54WT, Tel: 07599672607; Email: m.alshukri@edu.salford.ac.uk
}

\section{Research Article}

Volume 3 Issue 1

Received Date: March 20, 2019

Published Date: April 26, 2019

DOI: $10.23880 /$ ppej-16000185

\section{Abstract}

The MFrac software is an application used for fracture design and treatment analysis. An MFrac simulation is done to simulate the hydraulic fracturing in real life application in the oil fields. The MFrac simulates and calculates the real hydraulic fracturing in practice. The purpose of this research is to simulate the hydraulic fracturing in real life application in the oil fields to calculate the real hydraulic fracturing parameters. The aim of using MFrac is to get the fracture length, the fracture efficiency versus time, stress gradient, stress, young's modulus, Poisson's ratio and toughness at any certain true vertical depth (TVD).

Keywords: Simulate; Hydraulic fracturing; Fracture design; Treatment analysis; Real life

\section{Introduction}

MFrac makes it easy to design a treatment plan using established engineering design principles to increase a recovery, target the most productive plays while avoiding trouble zones, and optimize treatment schedules.

MFrac gives engineers the ability to create and execute efficient well stimulation designs in both conventional and unconventional plays, maximizing production and extending the life of a well. By more effectively managing a planning process and integrating real-time data, minifracs, hydraulic fracturing, well production, and economics, to gain confidence in a treatment plan and arrive at more meaningful reserves estimation.

For more than 25 years, engineers have trusted MFrac Suite software to provide reliable hydraulic fracturing predictions for enhanced investment decisions, better well placements, optimized stimulation treatments, and increased ultimate recovery.

The scope of this work is to investigate the role of MFrac in simulating the hydraulic fracturing to enhance permeability of unconventional shale reservoirs. MFrac simulation and orientation effect the Geomechanical Properties of Shale Rock, such as permeability and porosity.

Fracking is the procedure of injecting high-pressure liquids (as high as $10 \mathrm{k} \mathrm{psi}$ ) into rocks to fracture them $[1,2]$. These artificial fractures are kept open via proppants, for example, sand or ceramic particles. Fracking includes drilling down to about $2 \mathrm{~km}$ vertically, after that laterally outwards for around $3 \mathrm{~km}$ [3]. Shale encompasses several small pores where oil and natural gas may be entombed but this porosity is not interconnected, which render shales with ultra-low 


\section{Petroleum \& Petrochemical Engineering Journal}

permeability [4]. In order to release oil and gas, permeability must be initiated through hydraulic fracturing which creates thin, fluid-filled fissures which enable the interconnection of pores in mudstones; this enables oil resources and gas to move out via the rock and towards the oil well $[5,6]$.

Hydraulic fracturing is the process when injecting highpressure fluids (sometimes as high as $10 \mathrm{k} \mathrm{psi}$ ) into rocks to fracture them [4].

\section{Material and Methods}

The six shale samples from Eagleford, Mancos and Marcellus reservoirs were porosity found using CT scan and permeability found using Nano-Perm machine (Table 1).

\begin{tabular}{|c|c|c|c|c|}
\hline Rock type & Young's Modulus & Poisson's Ratio & Permeability, mD & CT scan Porosity \% \\
\hline Eagleford, PD & $4.6 \mathrm{e}+06$ & 0.26 & 0.0078 & $5.76 \%$ \\
\hline Eagleford, PL & $4.5 \mathrm{e}+06$ & 0.25 & 0.0076 & $5.08 \%$ \\
\hline Mancos, PD & $4.4 \mathrm{e}+06$ & 0.27 & 0.0085 & $5.05 \%$ \\
\hline Mancos, PL & $4.4 \mathrm{e}+06$ & 0.27 & 0.0084 & $5.45 \%$ \\
\hline Marcellus, PD & $4.3 \mathrm{e}+06$ & 0.28 & 0.0084 & $5.25 \%$ \\
\hline Marcellus, PL & $4.3 \mathrm{e}+06$ & 0.28 & 0.0084 & $5.76 \%$ \\
\hline
\end{tabular}

Table 1: Physical Properties of Eagle Ford, Mancos and Marcellus Shales.

The MFrac software is an application used for fracture design and treatment analysis. An MFrac simulation was done to simulate the hydraulic fracturing in real life application in the oil fields. The MFrac simulates and calculates the real hydraulic fracturing.

The core samples were simulated via MFrac. Graphs and a summary report of open hydraulic fracturing technique were created. The simulator applies continuous coefficients follow-on from MFrac plan and approximation simulator, using steady boundary circumstances in a comparable creation. The net load data, in the bar, gained through MFrac is utilised as a limit condition to MProd imitation. MFrac Simulation was outlined and briefly explained the methodology applied in MFast simulator is analogous to a taken analogy: The simulator utilises continuous coefficients resulting from MFrac design and estimation simulator, using steady boundary conditions in a similar creation. A production fraction regarding flow rate and volume is before planned for respective iteration. The net burden data, in the bar, is obtained via MFrac is utilised as a limit condition to MProd simulation.

\section{Fracability Evaluation in Shale Reservoirs}

Brittleness is considered one of the most significant mechanical properties of rock, which has been integrated in nearly all shale petrophysics reports of unconventional reservoirs $[7,8]$.

It is presumed that formation contains high brittleness is simple to fracture $[8,9]$, but this presumption is not always right as the formation of higher brittleness may be a fracture barrier, i.e., dolomitic limestone has a high brittleness, but in shale reservoirs, it is a rupture fence since in shale formation the fracture gradient is less than that of dolomitic limestone structure [10].

The quantity of stress that may be applied prior the rock shift to the next form of deformation relies on the rock type \& composition, temperature, time the rock is kept under stress and rock location, i.e., When the rock is at the Earth's surface, it generally breaks relatively quicker than if it is underground, when stress is placed [11] as shown in Eq. 1.

Where,

$$
\operatorname{stress}(\sigma)=\frac{\text { force }(\mathrm{F})}{\operatorname{area}(\mathrm{A})}
$$

$F=$ force (Newton: $\mathrm{kg}-\mathrm{m}^{2} / \mathrm{sec}^{2}$ ),

$A=\operatorname{area}\left(\mathrm{m}^{2}\right)$ 


\section{Petroleum \& Petrochemical Engineering Journal}

\section{MFrac Simulation}

The simulation required data: include the attained parameters, such as pump rate, bottomhole pressures, and pressures at the surface in addition to proppant concentration. Nitrogen or maybe carbon dioxide inoculation rates vs. calculated time.

The minifrac is used in the MFrac simulator to standardise the reservoir stresses, fracturing model, fracturing efficiency, and volume of the pad before starting the real pumping of the fracking process. The following 6 shale samples from Eagleford, Mancos and Marcellus reservoirs were scanned. The porosity was found using Liquid Saturation Method and permeability were found using the Nano-Perm machine. The core samples were simulated via MFrac and. Graphs and a summary report of open hydraulic fracturing technique were created. The simulator applies continuous coefficients follow-on from MFrac plan and approximation simulator, using steady boundary circumstances. A production fraction regarding flow rate and volume is pre-planned for respective iteration. The net burden data, in the bar, obtained via MFrac is applied as a boundary condition.

\section{Findings of the Research}

The following 6 shale samples from Eagleford, Mancos and Marcellus reservoirs were scanned, and the porosity was found using CT scan and permeability were found using the Nano-Perm machine. The simulation of MFrac was summarised and briefly studied the methodology used in MFast simulation is like a reserved analogy: The simulator applies continuous coefficients follow-on from MFrac plan and approximation simulator, using steady boundary circumstances in a comparable creation. The net load data, in the bar, is gained through MFrac utilised as a boundary condition to MProd imitation.

\section{Results}

This study used MFrac Simulation Graphs. The data of this MFrac simulation are taken from an oil field and used to characterise the field reservoir. MFrac was used to investigate the fracture profile that would be experimented by the shale sample. MFrac is applied to find the fracture length, the fracture efficiency versus time, stress gradient, stress, young's modulus, Poisson's ratio and toughness, as shown in Figure A4.
The stress gradient, stress, Young's Modulus and Poisson's Ratio for the following 6 shale samples from Eagleford, Mancos and Marcellus reservoirs were found as shown in Figure A4.

\section{Discussion}

MFrac data may contain pump rate, pressures of bottomhole and surface, proppant concentration, and $\mathrm{CO} 2$ or nitrogen injection rates vs time. The simulation of MFrac was summarised and briefly studied the methodology used in MFast simulation: The simulator applies continuous coefficients follow-on from MFrac plan and approximation simulator, using steady boundary circumstances in a comparable creation. A production fraction concerning flow rate and volume is prearranged for correspondingly iteration. The net load data, in the bar, is gained through MFrac utilised as a boundary condition to MProd imitation. The simulator utilises continuous coefficients resulting from MFrac design and estimation simulator, using steady boundary conditions in a similar creation. A production fraction regarding flow rate and volume is pre-planned for respective iteration.

\section{Conclusions}

MFrac makes it easy to design a treatment plan using established engineering design principles to increase a recovery, target the most productive plays while avoiding trouble zones, and optimize a treatment schedule. MFrac gives engineers the ability to create and execute efficient well stimulation designs in both conventional and unconventional plays, maximizing production and extending the life of a well. By more effectively managing a planning process and integrating real-time data, minifracs, hydraulic fracturing, well production, and economics, to gain confidence in a treatment plan and arrive at more meaningful reserves estimation.

\section{References}

1. Laffin M, Kariya M (2011) Shale Gas and Hydraulic Fracking. 20th World Petroleum Congress, World Petroleum Congress, Qatar, pp: 23.

2. Naidu RN, Rylance M (2017) A Simple Method for Identifying Fracture Initiation Pressure. SPE/IADC Drilling Conference and Exhibition, Society of Petroleum Engineers, The Netherlands, pp: 24.

3. Pettegrew J, Qiu J, Zhan L (2016) Understanding Wolfcamp Well Performance-A Workflow to Describe 


\section{Petroleum \& Petrochemical Engineering Journal}

the Relationship between Well Spacing and EUR. SPE/AAPG/SEG Unconventional Resources Technology Conference, Unconventional Resources Technology Conference, USA, pp: 11.

4. Indraratna B, Ranjith PG, Gale W (1999) Deformation and Permeability Characteristics of Rocks with Interconnected Fractures. $9^{\text {th }}$ ISRM Congress, International Society for Rock Mechanics and Rock Engineering, pp: 6.

5. Huang J, Safari R, Mutlu U, Burns K, Geldmacher I, et al. (2014) Natural-Hydraulic Fracture Interaction: Microseismic Observations and Geomechanical Predictions. SPE/AAPG/SEG Unconventional Resources Technology Conference, Unconventional Resources Technology Conference, USA, pp: 22.

6. Akrad OM, Miskimins JL, Prasad M (2011) The Effects of Fracturing Fluids on Shale Rock Mechanical Properties and Proppant Embedment. SPE Annual Technical Conference and Exhibition, Society of Petroleum Engineers, USA.

7. Jarvie DM, Hill RJ, Ruble TE, Pollastro RM (2007) Unconventional shale-gas systems: The Mississippian Barnett Shale of north-central Texas as one model for thermogenic shale-gas assessment, AAPG Bull 91(4): 475-499.

8. Rickman R, Mullen MJ, Petre JE, Grieser WV, Kundert D (2008) A Practical Use of Shale Petrophysics for Stimulation Design Optimization: All Shale Plays Are Not Clones of the Barnett Shale. SPE Annual Technical Conference and Exhibition, Society of Petroleum Engineers, USA, pp: 11.

9. Kundert DP, Mullen MJ (2009) Proper Evaluation of Shale Gas Reservoirs Leads to a More Effective Hydraulic-Fracture Stimulation. SPE Rocky Mountain Petroleum Technology Conference, Society of Petroleum Engineers, Colorado, pp: 11.

10. Bruner KR, Smosna R (2011) A Comparative Study of the Mississippian Barnett Shale, Fort Worth Basin, and Devonian Marcellus Shale, Appalachian Basin. National Energy Technology Laboratory (NETL), U.S. Department of Energy, pp: 1-118.

11. Liao HJ, Han J, Sugiyam M, Akaishi M (2009) Study on stress-strain relationship based on strain space. ISRM International Symposium on Rock MechanicsSINOROCK, International Society for Rock Mechanics and Rock Engineering, China. 